\title{
CARACTERÍSTICAS DO CONSUMO RESIDENCIAL DE LENHA E CARVÃO VEGETAL
}

\author{
Bruna Mariá dos Passos ${ }^{1}$, Flávio José Simioni ${ }^{2 *}$, Tamires Liza Deboni ${ }^{3}$, Beatriz Lima Santos Klienchen Dalari ${ }^{4}$ \\ ${ }^{1}$ Universidade do Estado de Santa Catarina, Curso de Engenharia Ambiental, Lages, Santa Cat arina, Brasil - brumariapassos@gmail.com, \\ beatriz.lskd@hotmail.com \\ ${ }^{2 *}$ Universidade do Estado de Santa Catarina, Centro Agroveterinário, Depart amento de Engenharia Ambiental, Lages, SC, Brasil - \\ flavio.simioni@udesc.br \\ ${ }^{3}$ Universidade do Estado de Santa Catarina, Programa dePós-Graduação em Ciências Ambientais, Lages, SC, Brasil- \\ tamideboni@yahoo.com.br
}

Recebido para publicação: 02/02/2015 - Aceito para publicação: 16/12/2015

\begin{abstract}
Resumo
Objetivou-se caracterizar o perfil do consumo de lenha e carvão vegetal nas residências urbanas de Lages/SC e identificar as características socioeconômicas que influenciam na quantidade consumida. Foram amostradas aleatoriamente 178 residências, por meio de um questionário estruturado, aplicado durante o mês de fevereiro de 2014. As informações coletadas proporcionaram quantificar o consumo de lenha e de carvão vegetal nas residências e caracterizar sua utilização e algumas características dos domicílios. Um conjunto de oito variáveis explicativas foram consideradas para avaliar a quantidade consumida de lenha ou carvão vegetal, separando as residências em dois grupos - as que consomem e as que não consomem. Os dados foram analisados utilizando-se estatística descritiva, correlação linear e análise de componentes principais (ACP). A lenha é consumida em 38,2\% dos domicílios entrevistados, com quantidade predominante de 0,1 a 2 st/ano (780 kg/domicílio/ano), enquanto que $36 \%$ consomem carvão vegetal, predominantemente até $15 \mathrm{~kg} / \mathrm{mês}$ (141,7 kg/domicílio/ano). A lenha é adquirida através de compra, preferencialmente em pedaços para uso em fogão ou lareira, tanto para cocção de alimentos como para aquecimento. As principais variáveis que estão associadas ao consumo de lenha foram a disponibilidade de fogão e lareira no domicílio e o número de pessoas, enquanto que para o carvão vegetal foi a produção de churrasco.

Palavras-chave: Energia de biomassa; carvão vegetal; consumo residencial.
\end{abstract}

\section{Abstract}

Characteristics of the consumption of firewood and charcoal in urban housing. The aim of this work was to characterize the profile of consumption of firewood and charcoal in urban housing of Lages/SC, identifying the socio-economic characteristics influencing the amount consumed. Were sampled randomly 178 homes using a survey, applied during the month of February of 2014. The information collected provided quantifying the use of firewood and charcoal in homes and characterize their use, such as the form of production, consumption purposes, species and types of wood used, some of the household characteristics (location, type and ownership of the property). The firewood was consumed in $38.2 \%$ of the households interviewed, with predominant amount of 0.1 to 2 st per year $(780 \mathrm{~kg} /$ household $/ \mathrm{year})$; while $36 \%$ use charcoal, predominantly up to $15 \mathrm{~kg} /$ month $(141.7 \mathrm{~kg} /$ household/year). The firewood is acquired through purchase from local suppliers, preferably in pieces for use on stove or fireplace for cooking food as a source of heating. The main variables that are associated with the consumption of firewood were the availability of stove and fireplace in the home and the number of people, while for charcoal was for preparing barbecue. Keywords: Biomass energy; vegetal coal; residential consumption.

\section{INTRODUÇÃO}

A madeira é um importante recurso natural que historicamente serviu como fonte de energia, primeiramente para aquecimento e cocção de alimentos e, posteriormente, para a promoção do avanço tecnológico (fornos, caldeiras, indústria moveleira, geração de energia a partir de biomassa), colaborando para o desenvolvimento da sociedade humana (BRITO, 2007). Trata-se, portanto, de uma importante fonte de energia primária, tanto para países desenvolvidos como para parcelas significativas da população dos países em desenvolvimento.

No cenário mundial, é válido ressaltar que o uso da madeira para energia é mais evidente em países em desenvolvimento, servindo como um componente de vital importância no suprimento de energia primária 
(BRITO, 2007). De acordo com o autor, o uso doméstico e industrial da lenha soma mais da metade do volume total de madeira mundialmente consumida para todas as finalidades. Um recente estudo realizado por Matsika et al. (2013) na África do Sul ressalta que, geralmente, a lenha é coletada de florestas comuns e campos agrícolas próximos ao domicílio e/ou aldeia, variando com o padrão de assentamento da região. Os autores chamam a atenção para essa forma de exploração, que aumentou a preocupação com uma possível demanda por lenha maior do que a oferta nesses países.

Analisando a situação do Brasil, Sgarbi (2013) relata que o padrão de consumo de lenha brasileiro contrasta com o perfil observado em economias emergentes, como China, Índia, África do Sul e México. Enquanto que nesses países a lenha é mais utilizada no setor residencial, no Brasil, grande parcela de lenha é utilizada pe lo setor industrial.

De acordo com o Ministério de Minas e Energia (BRASIL, 2015), a lenha reduziu sua participação no consumo final de energia do país de 8,2\% em 2005 para 6,3\% em 2014. Já o carvão vegetal passou de 3,2\% para 1,5\% no mesmo período. O consumo total de lenha passou, no período de 2005 a 2014, de 91.676 mil para 79.768 mil toneladas, sendo que a transformação em carvão vegetal e o consumo final em residências respondem atualmente por $31,1 \%$ e $24,7 \%$ do consumo total de lenha, respectivamente. Enquanto esses dois setores reduziram sua partic ipação percentual, o consumo industrial au mentou seu consumo de lenha.

O Brasil tem apresentado crescente substituição da lenha da extração vegetal de origem nativa pelo suprimento via florestas plantadas, cuja participação da lenha da silvicultura em relação ao total consumido passou de cerca de 20\% em 1990 para mais de 70\% em 2013 (IBGE, 2014). Vários problemas ambientais são decorrentes da exploração de florestas naturais, tais como a perda de biodiversidade, desproteção dos mananciais e redução de regimes de chuva, podendo até levar à escassez dessa fonte de energia. Com essas preocupações, desencadeou-se uma maior ação fiscalizadora dos órgãos ambientais, o que resultou em aumento da produção de madeira a partir de florestas plantadas, principalmente na região Sul e Sudeste (UHLIG, 2010). Ao seu favor, o Brasil apresenta vantagens competitivas para a produção florestal, principalmente relacionada à produtividade das coníferas e folhosas em plantios florestais com foco na produção de madeira (IBA, 2014).

Poucos estudos foram realizados no Brasil para determinar o consumo de lenha nas residências. Vale $e t$ al. (2003) verificaram o uso da lenha para a cocção de alimentos em u ma pequena comunidade rural no estado de Goiás. Mata e Souza (2000) também avaliaram a quantidade de lenha consumida para cocção de alimentos e para aquecimento residencial em um distrito no estado de Minas Gerais, tanto em áreas rurais como em áreas urbanas com características rurais. Para os autores, a ausência de estudos detalhados que propõem a regulação da produção de lenha seria o principal motivo da crise de oferta de lenha no meio rural.

Nes se contexto, o objetivo do presente trabalho foi caracterizar o perfil do consumo de lenha e carvão vegetal nas residências urbanas de Lages/SC, identificando as características socioeconômicas que influenciam a quantidade consumida.

\section{MATERIAL E MÉTODOS}

A pesquisa teve como área de abrangência as residências pertencentes à cidade de Lages, região serrana de Santa Catarina. Lages possui uma população estimada, para o ano de 2015, de 158.732 habitantes, Produto Interno Bruto (PIB) per capita, para o ano de 2012, de $\mathrm{R} \$ 21.349,94$ reais e Índice de Desenvolvimento Hu mano Municipal (IDHM), para o ano de 2010, de 0,77 (IBGE, 2015).

Uma população de 48.403 domicílios permanentes urbanos foi identificada pelo censo demográfico de 2010 (IBGE, 2015). A amostra foi definida a partir de um levantamento piloto (pré-amostra), segundo critérios para determinação do tamanho de uma amostra para estimativa da média definidos por Silva et al. (2011). Considerando o emprego do fator de correção para população finita, seria necessário amostrar aleatoriamente 155 residências para a estimativa da média da quantidade consumida de lenha e carvão vegetal em residências, considerando $95 \%$ de confiança e um erro máximo de $0,15 \mathrm{st} / \mathrm{ano}$ para lenha e de $1,2 \mathrm{~kg} / \mathrm{mês}$ para carvão vegetal. Assim, foram entrevistadas 215 residências, das quais 37 foram excluídas por não terem apresentado todas as informações necessárias para as análises, resultando em 178 a mostras válidas.

Os dados foram coletados utilizando-se um questionário como instrumento, aplicado diretamente nas residências, durante o mês de fevereiro de 2014. Inicialmente, os dados foram analisados considerando estatísticas descritivas, tais como média, coeficiente de variação e participação percentual, como também a correlação linear simples entre as variáveis. Posteriormente, realizou-se a análise de componentes principais (ACP), agrupando as residências em duas categorias: CONSOME e NÃO CONSOME, co m o intuito de verificar quais variáveis estão mais associadas ao consumo de lenha e carvão vegetal. As residências classificadas como CONSOME são aquelas que realizaram algum consumo de lenha ou carvão vegetal no ano de 2013, enquanto que as classificadas como NÃ O CONSOME não efetivara m nenhum consumo em 2013.

As variáveis exp licativas foram: 
a) Quantidade: indica a quantidade consumida em termos absolutos. Para a lenha, considerou-se a unidade metro estéreo (st) consumidas no ano de 2013, utilizando-se, como relação de equivalência, 1 metro estéreo $=500 \mathrm{~kg}=1000$ pedaços de lenha. Para o carvão vegetal, a unidade foi em $\mathrm{kg} / \mathrm{mês}$;

b) Localização: indica se a residência está sediada no centro da cidade de Lages ou fora dele. A variável é binária (dummy) e admite valor zero para as residências que estão situadas no centro de Lages e um para as sediadas nos bairros;

c) Lareira: indica se a residência possui lareira. A variável é binária (dummy) e admite valor zero para as que não possuem lareira e u m para as que possuem;

d) Casa: a variável é binária (dummy) e admite valor zero para as residências que não são casas e um quando a residência é u ma casa;

e) Apto: a variável é binária (dummy) e ad mite valor zero para as residências que não são apartamentos e um quando a residência é um apartamento;

f) Pessoas: indica o número de pessoas que residem no imóvel;

g) Renda: a variávelé ordinal e representa a renda familiar mensal, atribuindo-se ze ro quando a fa mília não tem renda, um para renda de até dois salários mínimos mensais, dois para renda de dois a cinco salários mínimos mensais, três para renda de cinco a dez salários mínimos mensais e quatro para renda de dez salários mínimos mensais ou mais;

h) Fogão: indica se a residência possui fogão para uso da lenha. A variável é binária (dummy) e admite valor zero para as residências que não possuem fogão e u m para as que possuem;

i) Churrasco: indica o principal uso do carvão vegetal na residência. A variável é binária (dummy) e admite valor zero para as residências que não utilizam o carvão para churrasco e um para as que utilizam.

Além desse conjunto de variáveis explicativas utilizadas na ACP, também foram identificadas a forma de obtenção da lenha e do carvão vegetal (compra, produção própria, doação ou outra forma), seus principais usos (local ou equipamento utilizado, sua finalidade e periodicidade), tipo de lenha (toretes, resíduos da indústria, cascas, galhos, pedaços ou outros) e o perfil das residências entrevistadas (localização, tipo e propriedade do imóvel).

Para verificar a relação existente entre a quantidade consumida de lenha e de carvão vegetal e as variáveis explicativas, calculou-se o coeficiente de correlação linear simples entre as variáveis, obtido através da expressão:

$$
r=\frac{\sum_{i=1}^{n}\left(x_{i}-\bar{x}\right)(y-\bar{y})}{\sqrt{\left(\sum x_{i}-\bar{x}\right)^{2} \cdot\left(\sum y_{i}-\bar{y}\right)^{2}}}
$$

$\mathrm{O}$ valor de $\mathrm{r}$ varia entre -1 e +1 , sendo que $\mathrm{r}$ próximo a +1 significa a existência de alta correlação positiva entre as variáveis, e próximo a -1 significa a existência de alta corre lação negativa. Por outro lado, o $\mathrm{r}$ próximo a zero significa a inexistência de correlação entre as variáveis consideradas. A significância do coeficiente de corre lação linear foi identificada pelo teste t, utilizando-se a seguinte expressão:

$$
t_{c}=\frac{r \sqrt{n-2}}{\sqrt{1-r^{2}}}
$$

Quanto ao procedimento de análise estatística multivariada, utilizou-se como primeiro passo a análise de Detrended Correspondence Analysis (DCA) para a obtenção do comprimento do gradiente. Como o comprimento do gradiente indicou uma resposta linear em relação aos eixos, realizou-se a Análise de Componentes Principais (ACP) para a separação dos grupos avaliados (CONSOME e NÃO CONSOME) e relacioná-los com as variáveis explicativas, dando igual ênfase a todas elas ao mesmo tempo, conforme recomendação de Ter Braak e Smilauer (1998).

\section{RES ULTADOS E DISCUSSÃO}

A lenha é consumida por $38,2 \%$ dos domicílios entrevistados, com quantidade predominante de 0,1 a 2 st/ano (Tabela 1), resultando em um consumo médio estimado para o município de Lages de $0,596 \mathrm{st}$ /domicílio/ano (com coeficiente de variação de $144,4 \%$ ) ou $0,201 \mathrm{st} /$ pessoa/ano. O peso estimado para esse consumo é de 297,8 kg/domicílio/ano ou 100,7 kg/pessoa/ano. Os dados evidenciam que as residências que consomem lenha apresentam mais pessoas por domicílio $(3,3), 99,0 \%$ são casas e $89,5 \%$ são proprietários dos imóveis. Já para os que não consomem lenha, o número méd io de pessoas é de 2,8 , com um maior percentual de 
apartamentos $(22,7 \%)$ e de imóveis alugados $(22,7 \%)$. Quanto à renda familiar, não se observaram diferenças importantes entre os dois grupos avaliados (Tabela 1).

Tabela 1. Quantidade e características dos domicílios segundo as diferentes escalas de consumo de lenha em Lages/SC - 2013.

Table 1. Quantity and characteristics of households according to the different scales of firewood consumption in Lages/SC - 2013.

\begin{tabular}{|c|c|c|c|c|c|c|c|c|c|c|c|}
\hline \multirow{2}{*}{$\begin{array}{l}\text { Consumo } \\
\text { (st/ano) }\end{array}$} & \multicolumn{2}{|c|}{ Domicílio } & \multirow{2}{*}{$\begin{array}{l}\mathbf{N}^{\circ} \text { de } \\
\text { pessoas }\end{array}$} & \multicolumn{2}{|c|}{$\begin{array}{c}\text { Tipo de } \\
\text { domicílio }(\%)\end{array}$} & \multicolumn{2}{|c|}{$\begin{array}{l}\text { Posse do domicílio } \\
(\%)\end{array}$} & \multicolumn{4}{|c|}{$\begin{array}{c}\text { Renda familiar } \\
\text { (Salários mínimos) }(\%)\end{array}$} \\
\hline & $\mathrm{N}^{\mathrm{o}}$ & $\%$ & & Casa & Apto & Próprio & Alugado & Até 2 & 2 a 5 & 5 a 10 & $10 \mathrm{ou}+$ \\
\hline Não consome & 110 & 61,8 & 2,8 & 77,3 & 22,7 & 77,3 & 22,7 & 34,5 & 48,2 & 17,3 & 0,0 \\
\hline De 0,1 a 1,0 & 35 & 19,7 & 3,2 & $\overline{97,1}$ & 2,9 & 82,9 & 17,1 & 22,9 & 57,1 & 14,3 & 5,7 \\
\hline De 1,1 a 2,0 & 26 & 14,6 & 3,3 & 100 & 0,0 & 100 & 0,0 & 38,5 & 50,0 & 3,8 & 7,7 \\
\hline De 2,1 a 3,0 & 7 & 3,9 & 3,3 & 100 & 0,0 & 85,7 & 14,3 & 28,6 & 57,1 & 14,3 & 0,0 \\
\hline CONSOME & 68 & 38,2 & 3,3 & 99,0 & 1,0 & 89,5 & 10,5 & 30,0 & 54,8 & 10,8 & 4,5 \\
\hline
\end{tabular}

Para a cat egoria CONSOME, o $\mathrm{n}^{\circ} \mathrm{e} \%$ de domicílio refere-se ao total das três classes de consumo, e as demais variáveis $\left(\mathrm{n}^{\circ}\right.$ de pessoas, tipo e posse do domicílio e renda familiar) referem-se à média das três classes de consumo.

Considerando somente os domicílios que consomem lenha (68), o consumo méd io foi de 1,56 st/ano ou $0,53 \mathrm{st} /$ pessoa/ano (com coeficiente de variação de $42,0 \%$ e $54,7 \%$, respectivamente). O peso estimado para esse consumo chega a $779,4 \mathrm{~kg} /$ domicílio/ano ou $263,9 \mathrm{~kg} /$ pessoa/ano. O consumo médio de lenha estimado no presente trabalho $(779,4 \mathrm{~kg} / \mathrm{domic}$ lio/ano) é inferior aos resultados em outras regiões do Brasil. Vale et al. (2003) encontraram $3.847 \mathrm{~kg} /$ domic ílio/ano em u ma comunidade rural do estado de Goiás, López et al. (2000) reportaram um consumo de $3.657 \mathrm{~kg} / \mathrm{domic}$ ílio/ano no meio rural e Mata e Souza (2000) encontraram valores de $6.800 \mathrm{~kg} /$ domicílio/ano na área urbana (distrito) e 9.318,5 kg/domicílio/ano no meio rural.

Segundo Mata e Souza (2000), o consumo de lenha reduz em função do grau de urbanização. A diferença encontrada pode ser exp licada, ao menos em parte, pelo fato de que no meio urbano a lenha precisa ser adquirida através da compra, enquanto que no meio rural a lenha está disponível na propriedade rural. Outras características presentes nas comunidades rurais, tais como a produção de panificados, doces, carnes e derivados , demandam significativa quantidade de lenha para a sua preparação.

De acordo com a tabela 2, em $88,2 \%$ dos casos a lenha é adquirida através da compra diretamente de fornecedores locais. Nas demais situações, a lenha é recebida por doação de familiares (13,2\%) ou refere-se a produção própria $(1,5 \%)$. Verificou-se que, para 97,1\% dos consumidores, a lenha é adquirida em pedaços ou partida, ou seja, em formato para uso em fogão residencial. Poucos consumidores relataram outros formatos de lenha, tais como cascas $(2,9 \%)$ ou galhos (2,9\%). Simioni e Hoeflich (2009) relataram que as cascas e outros subprodutos da indústria madeireira de pínus são destinados para a indústria, objetivando a produção de energia térmica e elétrica, constituindo uma cadeia produtiva organizada na região de Lages.

Tabela 2. Quantidade de domicílios $\left(\mathrm{n}^{\mathrm{o}}\right.$ e $\left.\%\right)$ segundo as diferentes características de consumo de lenha em Lages/SC - 2013.

Table 2. Quantity of households (number and \%) according to the different characteristics of fire wood and charcoal consumption in Lages/SC - 2013.

\begin{tabular}{|c|c|c|c|}
\hline \multirow{2}{*}{\multicolumn{2}{|c|}{ Características do consumo de lenha }} & \multicolumn{2}{|c|}{ Quantidade } \\
\hline & & $\mathrm{N}^{\circ}$ de domicílios & $\%$ \\
\hline \multirow{3}{*}{ Forma de obtenção } & Compra & 60 & 88,2 \\
\hline & Recebida por doação & 9 & 13,2 \\
\hline & Produção própria & 1 & 1,5 \\
\hline \multirow{3}{*}{ Tipo de lenha } & Pedaços (lenha partida) & 66 & 97,1 \\
\hline & Galhos & 2 & 2,9 \\
\hline & Cascas & 2 & 2,9 \\
\hline \multirow{4}{*}{ Espécie de lenha } & Eucalipto & 10 & 14,7 \\
\hline & Bracatinga & 11 & 16,2 \\
\hline & Outras nativas & 39 & 57,4 \\
\hline & Não sabe & 8 & 11,8 \\
\hline \multirow{3}{*}{ Local de uso } & Fogão & 49 & 72,1 \\
\hline & Lareira & 17 & 25,0 \\
\hline & Churrasqueira & 4 & 5,9 \\
\hline
\end{tabular}


Quanto às espécies, 14,7\% utilizam o eucalipto (Eucalyptus sp.), 16,2\% a bracatinga (Mimosa scabrella), 57,4\% outras espécies nativas e 11,8\% não souberam identificar a principal espécie utilizada. Nota-se que parcela significativa da lenha é proveniente de florestas nativas, o que demanda políticas e ações objetivando o suprimento dessa demanda a partir de florestas plantadas. Em outras regiões, como em estabelecimentos comerciais em Aracaju/SE, Santos e Gomes (2009) também chamam a atenção para o estabelecimento de plantios florestais para o suprimento da demanda de lenha.

Seu principal uso ocorre em fogões residenciais $(72,1 \%)$, tanto para cocção de alimentos como para aquecimento da residência, seguido pelo uso em lareiras $(25,0 \%)$, sobretudo no período de inverno, e do uso em churrasqueiras $(5,9 \%)$, para a produção de churrasco.

O carvão vegetal é consumido por $36 \%$ dos domicílios entrevistados, com quantidade predominante de até $15 \mathrm{~kg} /$ mês. O consumo médio da amostra pesquisada foi de 50,9 kg/domicílio/ano ou 17,5 kg/pessoa/ano, com coeficiente de variação de $172,2 \%$ e 199,9\%, respectivamente. Considerando somente os domicílios que consomem carvão vegetal (64 domicílios), a quantidade média foi de $141,7 \mathrm{~kg} / \mathrm{domic}$ lio/ano ou $48,6 \mathrm{~kg} / \mathrm{pes}$ soa/ano, com coeficiente de variação de $65,3 \%$ e $89,5 \%$, res pectivamente. Os dados evidenciam que as residências que consomem carvão apresentam mais pessoas por domicílio $(3,3), 91,0 \%$ são casas e $90,5 \%$ são proprietários dos imóveis. Já para os que não consomem carvão vegetal, o nú mero médio de pessoas é de 2,9, com um maior percentual de apartamentos $(17,5 \%)$ e de imóveis alugados $(21,1 \%)$. Quanto à renda familiar, não se observaram diferenças importantes entre os dois grupos avaliados (Tabela 3). Em 100\% dos casos, o uso do carvão se dá em churrasqueiras, para a produção de churrasco, e é adquirido através de compra no varejo local.

Tabela 3. Quantidade de domicílios $\left(\mathrm{n}^{\mathrm{o}}\right.$ e \%) e características segundo as diferentes escalas de consumo de carvão vegetal em Lages/SC - 2013.

Table 3. Quantity of households (number and \%) and characteristics according to the different scales of charcoal consumption in Lages/SC - 2013.

\begin{tabular}{|c|c|c|c|c|c|c|c|c|c|c|c|}
\hline \multirow[t]{2}{*}{$\begin{array}{l}\text { Consumo } \\
\text { (kg/mês) }\end{array}$} & \multicolumn{2}{|c|}{ Domicílio } & \multirow[t]{2}{*}{$\begin{array}{l}\mathrm{N}^{\circ} \text { de } \\
\text { pessoas }\end{array}$} & \multicolumn{2}{|c|}{$\begin{array}{c}\text { Tipo de } \\
\text { domicílio } \\
(\%)\end{array}$} & \multicolumn{2}{|c|}{$\begin{array}{c}\text { Posse do domicílio } \\
(\%)\end{array}$} & \multicolumn{4}{|c|}{$\begin{array}{c}\text { Renda familiar } \\
\text { (salários mínimos) }(\%)\end{array}$} \\
\hline & $\mathrm{N}^{\circ}$ & $\%$ & & Casa & Apto. & Próprio & Alugado & Até 2 & 2 a 5 & 5 a 10 & $10 \mathrm{ou}+$ \\
\hline $\begin{array}{c}\text { NÂO } \\
\text { CONSOME }\end{array}$ & 114 & 64,0 & 2,9 & 82,5 & 17,5 & 78,9 & 21,1 & 35,1 & 47,4 & 14,9 & 2,6 \\
\hline 0,1 a 5,0 & 28 & 15,8 & 3,1 & 85,7 & 14,3 & 82,1 & 17,9 & 42,9 & 53,5 & 3,6 & 0 \\
\hline 5,1 a 10,0 & 16 & 9,0 & 3,7 & 93,8 & 6,2 & 87,5 & 12,5 & 6,2 & 62,6 & 25,0 & 6,2 \\
\hline 10,1 a 15,0 & 13 & 7,3 & 3,1 & 84,6 & 15,4 & 92,3 & 7,7 & 38,5 & 38,5 & 23,1 & 0 \\
\hline 15,0 ou mais & 7 & 3,9 & 3,2 & 100,0 & 0 & 100 & 0 & 0 & 85,7 & 14,3 & 0 \\
\hline Consome & 64 & 36,0 & 3,3 & 91,0 & 9,0 & 90,5 & 9,5 & 21,9 & 60,1 & 16,5 & 1,5 \\
\hline
\end{tabular}

A análise preliminar à $\mathrm{ACP}$, através da matriz de correlação linear simples (Pearson), entre a quantidade consumida de lenha e de carvão vegetal e as variáveis explicativas selecionadas é apresentada na tabela 4. Para a lenha, com exceção da variável renda, todas as demais apresentaram corre lação significativa. Já para o consumo de carvão vegetal, as variáveis com correlação significativa foram o local, as pessoas e o churrasco. Uma correlação forte foi observada entre o consumo de lenha e a presença de fogão na residência $(r=0,7192)$ e entre o consumo de carvão vegetal e a preparação do churrasco $(r=0,7771)$.

Tabela 4. Correlação linear simples entre a quantidade consumida de lenha e carvão vegetal e as variáveis explicativas em Lages/SC.

Table 4. Simple linear correlation between the consumed quantity of firewood and charcoal and the explanatory variables in Lages/SC.

\begin{tabular}{l|ccc|ccc}
\hline \multirow{2}{*}{ Variável } & \multicolumn{3}{|c|}{ Lenha } & \multicolumn{3}{c}{ Carvão vegetal } \\
\cline { 2 - 7 } & Correlação (r) & $\mathrm{t}$ & Sig. & Correlação (r) & $\mathrm{t}$ & Sig. \\
\hline Local & 0,2134 & 2,897 & $*$ & 0,2129 & 2,891 & $*$ \\
Lareira $^{(1)}$ & 0,3321 & 4,670 & $*$ & --- & --- & --- \\
Fogão $^{(1)}$ & 0,7192 & 13,731 & $*$ & --- & --- & --- \\
Casa & 0,2571 & 3,530 & $*$ & 0,1044 & 1,393 & $\mathrm{~ns}$ \\
Apto & $-0,2337$ & $-3,188$ & $*$ & $-0,0696$ & $-0,926$ & $\mathrm{~ns}$ \\
Pessoas & 0,1877 & 2,535 & $* *$ & 0,1522 & 2,043 & $* *$ \\
Renda & 0,0177 & 0,235 & $\mathrm{~ns}$ & 0,1193 & 1,594 & $\mathrm{~ns}$ \\
Churrasco $^{(2)}$ & --- & --- & -- & 0,7771 & 16,378 & $*$ \\
\hline
\end{tabular}

* significativo pelo teste t bilateral ao nível de $1 \%$ de significância (t crítico = 2,576); ** significativo pelo teste t bilat eral ao nível de $5 \%$ de significância (t crítico $=1,960) ;{ }^{\text {ns }}$ não significativo; ${ }^{(1)}$ Não houve consumo de carvão vegetal em lareira e fogão; ${ }^{(2)} \mathrm{O}$ consumo de lenha para preparação de churrasco é reduzido, em apenas 5,9\% dos domicílios. 
A análise multivariada para o consumo de lenha mostrou que os eixos um e dois da ACP explicaram, respectivamente, 34 e 21,5\% da variabilidade dos dados, enquanto que os eixos três e quatro explicaram 17 e 11,4\%, respectivamente. Assim, 55,5\% da variabilidade total dos dados foram explicados pelas duas primeiras dimensões. O valor médio dos componentes principais representados através dos centroides da variável dependente (consumo de lenha) demonstra a nítida separação entre os do is grupos avaliados (Figura 1).

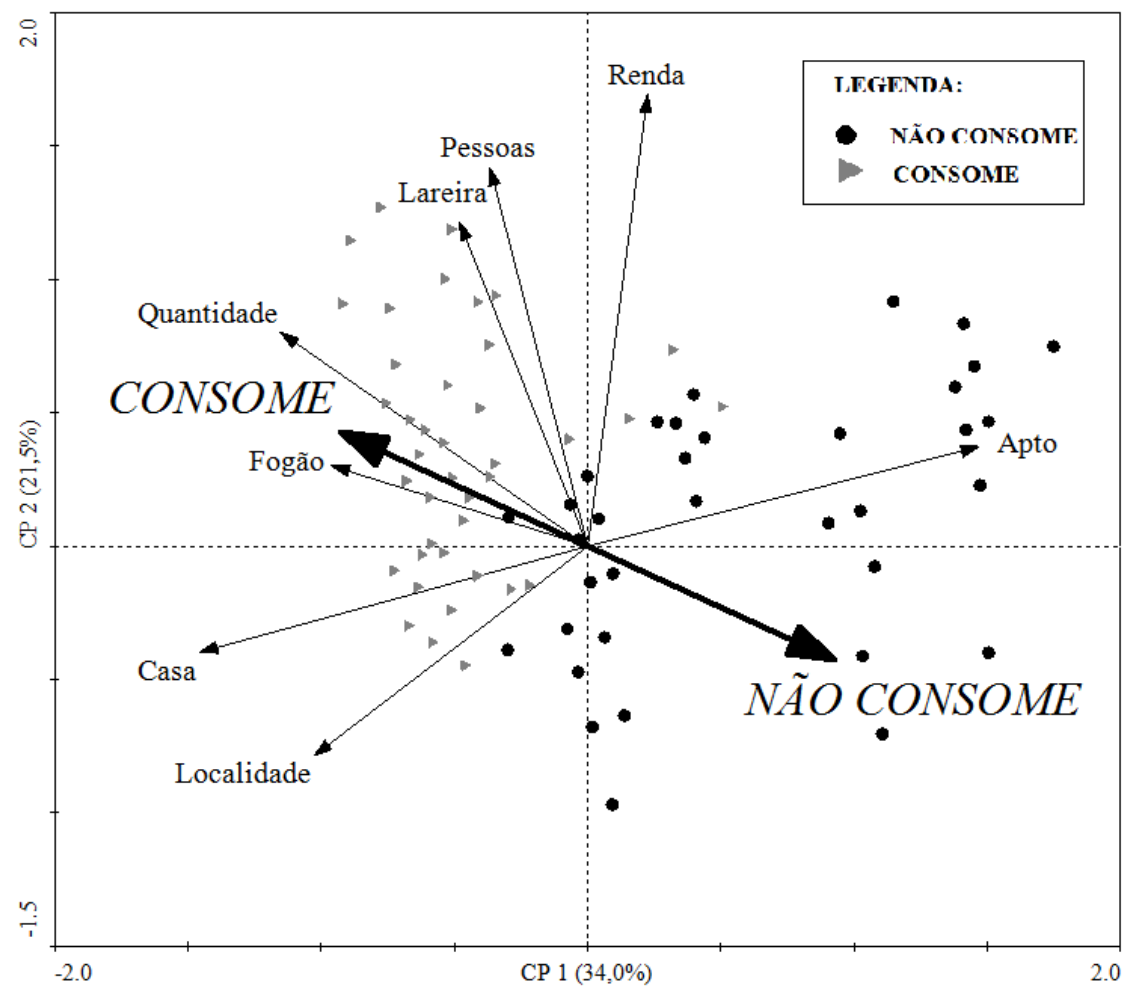

Figura 1. Relação entre os componentes principais $1(\mathrm{CP} 1=34,0 \%)$ e $2(\mathrm{CP} 2=21,5 \%)$, discriminando os grupos avaliados para o consumo de lenha (CONSOME e NÃO CONSOME), representados pelo valor médio dos componentes principais através dos centroides, e as variáveis explicativas selecionadas.

Figure 1. Relationship between the main components $1(\mathrm{CP} 1=34.0 \%)$ and $2(\mathrm{CP} 2=21.5 \%)$ listing the evaluated groups for the firewood consumption (DOES CONSUME and DOES NOT CONSUME), represented by the average value of the main components through centroids, and the explanatory variables selected.

De acordo com a figura 1, a principal variável que está associada ao consumo de lenha é a presença de fogão na residência, seguida da lareira e do número de pessoas. Já as variáveis casa e local apresentaram menor grau de associação com a quantidade consumida. A principal variável associada ao não consumo refere-se ao tipo de residência (apartamento). A variável renda não apresentou clara associação com a quantidade consumida de lenha.

Os entrevistados que residem em casa possuem maiores chances de terem em sua moradia lareira ou fogão a lenha, ao contrário de quem mora em apartamento, motivo pelo qual o consumo nesse caso possui correlação positiva. Além disso, casas, em geral, dispõem de um maior es paço para es tocar e armazenar a lenha. A predominância das casas nos bairros e dos apartamentos no centro explica a significância da variável localidade. López et al. (2000) sugeriu que pessoas que residem em domicílio próprio possuem um consumo menor em relação às que alugam, pois podem contar com equipamentos, como o fogão à lenha.

O número de pessoas que residem por domicílio também apresentou associação com a quantidade consumida de lenha, sobretudo na presença de crianças ou idosos, em que o consumo de lenha tem por finalidade o aquecimento nos períodos mais frios, uma vez que eles passam mais tempo na residência.

A variável renda apresentou baixa correlação com a quantidade consumida de lenha $(r=0,0177)$ e não houve significância. Correlações semelhantes também foram encontrados por Mata e Souza (2000), de -0,085 na área rural e 0,2401 na área urbana. A baixa correlação com a renda pode ser explicada por questões culturais, como é a prática de cocção de alimentos em fogão, e pela ocorrência de baixas temperaturas no período do inverno, fator que, independentemente da renda, demanda fontes de aquecimento residencial. Outras formas de 
aquecimento, como aquecedores elétricos ou condicionadores de ar, são substitutos para o fogão à lenha, principalmente para os residentes em apartamentos.

O preço de outras fontes de energia também influencia na escolha e na quantidade consumida de lenha. Famílias com menor renda ou renda irregular são sensíveis às variações de preços (DA VIS, 1998). Portanto, para o preparo de refeições que consomem mais energia, a população de baixa renda escolhe opções mais baratas, sendo a lenha o substituto favorito quando há um aumento de preço de outros combustíveis (SANGA; JANNUZZ, 2005).

Os autores Leach e Gowan (1987) e Davis (1998) também apresentaram os fatores renda familiar, número de pessoas na família, clima, cultura (dieta, modo de preparo de comidas), custo e eficiência de fogão como determinantes para a escolha do tipo de combustível utilizado como energia para cocção. Como observado por Mata e Souza (2000), o uso de lenha tende a diminuir à medida que as pessoas têm a possibilidade de adquirir tipos alternativos de fogão. O menor consumo, pode se dizer, está atrelado à evolução de consumo de gás liquefeito de petróleo, seu substituto natural na maior parte das residências brasileiras (BRITO, 2007).

De acordo com Sgarbi (2013), a baixa eficiência de combustão ou quando o sistema de exaustão de gases não é eficiente ou inexistente é fator de estímulo para a troca de fogões à lenha por fogões alternativos. De acordo com o autor, a combustão de lenha e outros combustíveis sólidos em ambientes não ventilados emite poluentes que podem causar doenças respiratórias, como infecção das vias aéreas inferiores em crianças. Quando a queima da madeira ocorre em condições inadequadas, pode causar emissões consideráveis de várias substâncias poluentes, como, por exemplo, o monóxido de carbono (CO), compostos orgânicos voláteis totais e fuligem, podendo alterar a qualidade tanto do ar interno como do externo (ASHARI et al., 2011).

Para o carvão vegetal, os eixos um e dois da ACP explicaram, respectivamente, 35,9 e 26,7\% da variabilidade dos dados, enquanto que os eixos três e quatro explicaram 19,5 e 8,3\%, respectivamente. Também neste caso, com explicação de $62,6 \%$ da variabilidade total dos dados, houve a nítida separação entre os dois grupos avaliados (Figura 2). O gráfico da ACP evidencia que a preparação do churras co e o número de pessoas no domicílio são as principais variáveis que estão associadas ao consumo de carvão nas residências, seguidas do local, casa e renda. Também neste caso, o não consumo está associado ao tipo de residência (apartamento).

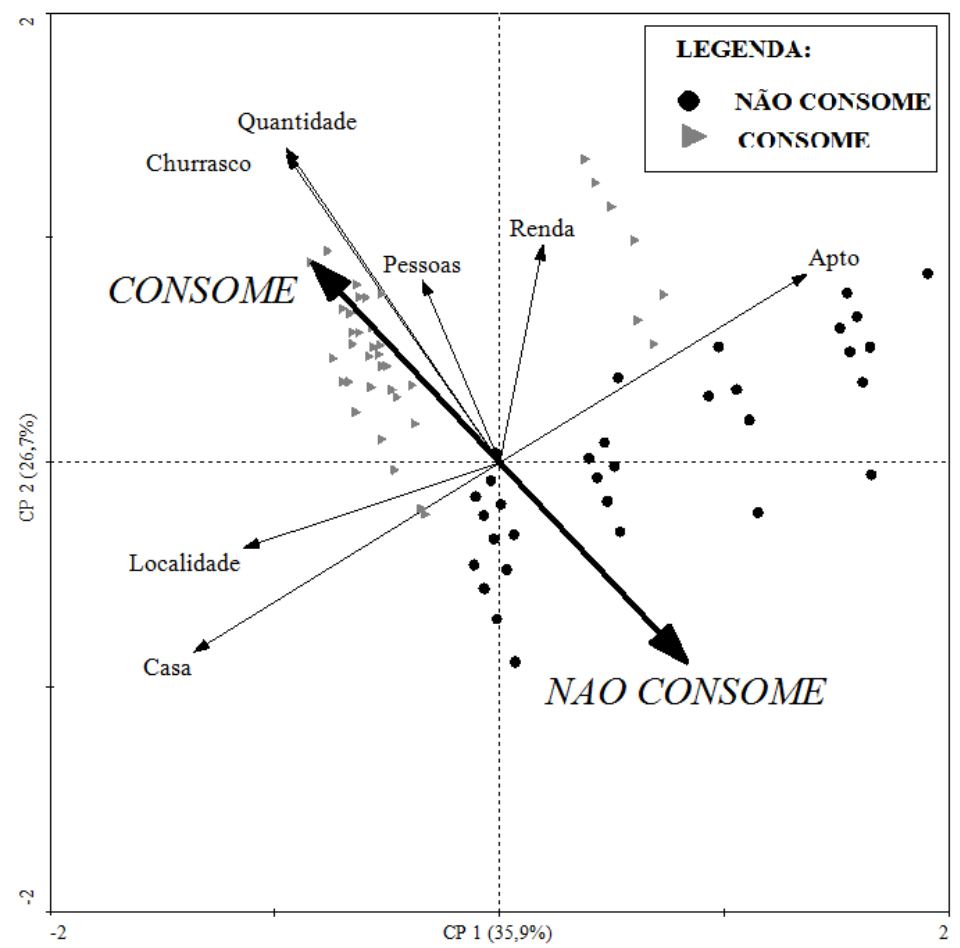

Figura 2. Relação entre os componentes principais $1(\mathrm{CP} 1=35,9 \%)$ e $2(\mathrm{CP} 2=26,7 \%)$ discriminando os grupos avaliados para o consumo de carvão vegetal (CONSOME e NÃO CONSOME), representados pelo valor médio dos componentes principais através dos centroides, e as variáveis explicativas selecionadas.

Figure 2. Relationship between the main components $1(\mathrm{CP} 1=35.9 \%)$ and $2(\mathrm{CP} 2=26.7 \%)$ listing the evaluated groups for the charcoal consumption (DOES CONSUME and DOES NOT CONSUME), represented by the average value of the main components through centroids, and the explanatory variables selected. 
Para o carvão vegetal, as associações com as variáveis casa, local, pessoas, renda e apartamento apresentaram resultados muito semelhantes quando comparadas com o consumo de lenha. Contudo, o consumo de carvão vegetal nas residências está intimamente relacionado com a sua utilização para o churrasco. Felfli et al. (2004) relata que 64\% do carvão vegetal produzido no estado de São Paulo são destinados para o consumo doméstico, na preparação do churrasco.

Segundo Uhlig (2010), o grande consumo residencial de carvão vegetal, principalmente na área urbana, é atribuído ao churrasco, que é um importante hábito cultural popular no país em todos os níveis de renda, o que explica a alta correlação da variável 'churrasco' com o consumo de carvão vegetal $(0,7771)$. Ainda de acordo com Uhlig (2010), a média nacional por domicílio foi estimada em $6,8 \mathrm{~kg} / \mathrm{mês}$ ou $81,6 \mathrm{~kg} / \mathrm{ano}$, cerca de $40 \%$ menor do que o obtido para a cidade de Lages, cuja média geral foi de 50,9 kg/domicílio/ano ou $141,7 \mathrm{~kg} /$ domicílio/ano, se considerada somente a população consumidora.

Morello (2011) chama a atenção para a necessidade de se analisar, além do consumo direto de lenha e carvão vegetal (sobretudo para cocção/aquecimento e para o churrasco, respectivamente), o consumo indireto baseado no padrão de consumo. De acordo com o autor, ao se analisarem dados do Brasil de 2002 e 2008 , o consumo direto de lenha e carvão vegetal mostra-se cadente com o nível de renda; em contraposição, o consumo indireto de lenha é ascendente. No conjunto, o consumo total de lenha cresce com a renda das famílias, mostrando-se imprescindível para a sociedade brasile ira.

\section{CONCLUS ÕES}

- A utilização da lenha como fonte energética é expressiva na região estudada, tanto para a cocção de alimentos como para aquecimento das residências nos períodos mais frios. É adquirida de fornecedores locais em pedaços para uso em fogão e lareiras, na sua maioria de espécies nativas, o que remete à preocupação quanto ao uso sustentável dos recursos florestais da região.

- O consumo de lenha está as sociado, principalmente, aos domicílios tipo casa, que dispõem de fogão e lareira, como também do número de pessoas no domicílio. A lenha é consumida em $38,2 \%$ dos domicílios e é adquirida em pedaços, pronta para uso em fogão ou lareira, com quantidade estimada de 1,56 st/ano ou $780 \mathrm{~kg} /$ domicílio/ano. Já o carvão vegetal é consumido em $36 \%$ dos domićlios, utilizado exclusivamente para a produção do churrasco, com quantidade estimada de $141,7 \mathrm{~kg} /$ domicílio/ano.

- O presente trabalho pretende contribuir para aumentar a confiabilidade das estimativas das quantidades consumidas de lenha e carvão vegetal nas residências do Brasil, de modo a auxiliar o planejamento dos plantios florestais visando atender essa demanda.

\section{REFERÊNCIAS}

ASHARI, A.; BERGSOE, N. C.; JENSEN, O. M.; CARVALHO, R. L. T. Impact of operating wood-burning stoves on indoor air quality. In: THE 12TH CONFERENCE OF INDOOR AIR 2011, 12., Austin Texas, 2011. Anais... International Society of Indoor Air Quality and Climate, Danish Building Research Institute, 2011.

BRASIL. Ministério de Minas e Energia. Empresa de Pesquisa e Energia - EPE. Balanço Energético Nacional: relatório final. Rio de Janeiro: RJ, 2015. 291 p.

BRITO, J. O. O uso energético da madeira. Es tudos Avançados, São Pau lo, v. 21, n. 59, p. 185-193, 2007.

DA VIS, M. Rural household energy consumption: the effects of access to electricity - evidence from South Africa. Energy Policy, v. 26, n. 3, p. 207 - 217, 1998.

FELFLI, F. F.; LUENGO, C. A.; ROCHA, J. D. Briquetes torrificados: viabilidade técnico-econômica e perspectivas no mercado brasileiro. In: ENCONTRO DE ENERGIA NO MEIO RURAL, 5., 2004, Campinas. Proceedings online... Disponível em: <http://www.proceedings.scielo.br/scielo.php?script=sci_arttext\&pid= MSC0000000022004000100035\&lng=en\&nrm=abn>. Acess o em: 30 jan. 2015.

INSTITUTO BRASILEIRO DE GEOGRAFIA E ESTATÍSTICA (IBGE). Cidades@. Disponível em: <http://cod.ibge.gov.br/233OG>. IBGE, 2015. Acesso em: 26 fev. 2015.

Produção da extração vegetal e da silvicultura - PEVS, 2014. Disponível em: <ftp://ftp.ibge.gov.br/Producao_Agricola/Producao_da_Extracao_Vegetal_e_da_Silvicultura_[anual]/2013/xls/b rasil_xls.zip>. Acesso em: 15 mai 2015. 
INDÚSTRIA BRASILEIRA DE ÁRVORES (IBA) 2014. Disponível em: <http://www.iba.org/shared/iba _2014_pt.pdf>. Acesso em: 15 maio 2015.

LEACH, G.; GOWAN, M. Household energy handbook: an interim guide and reference manual the World Bank. Washington: DC, 185 p, 1987.

LÓPEZ, J. C. F.; SILVA, M. L. da; SOUZA, A. L. Consumo residencial de lenha em Cachoeira de Santa Cruz, Viçosa/MG, Brasil. Re vista Árvore, Viçosa, v. 24, n.4, p. 423 - 428, 2000.

MATA, H. T. C.; SOUZA, A. L. Estimativa do consumo residencial de lenha num distrito do Estado de Minas Gerais, Brasil. Revista Árvore, Viçosa, v. 24, n. 1, p. 63 - 71, 2000.

MATSIKA, R.; ERASMUS, B. F. N.; TWINE, W. C. Double jeopardy: the dichotomy of fuelwood use in rural South Africa. Energy Policy, v. 52, p. 716 - 725, 2013.

MORELLO, T. F. Consumo de lenha e distribuição de renda no Brasil. Informações Fipe, p. 46-53, set. 2011. Disponível em: <http://www.fipe.org.br/publicacoes/downloads/bif/2011/9_46-53-thiag.pdf>. Acesso em: 30 jan. 2015.

SANGA, G. A.; JANNUZZ, G. M. Impacts of efficient stoves and cooking fuel substitution in family expenditures of urban households in Dar es Salaam, Tanzania. Energy Discussion Paper, Campinas, SP. n. $2.59 .1,18 \mathrm{p}, 2005$.

SANTOS, S. C. de J.; GOMES, L. J. Consumo e procedência de lenha pelos estabelecimentos comerciais de Aracaju/SE. Revista da Fapese, v. 5, n. 1, p. 155 - 164, 2009.

SGA RBI, F. A. Modelos de transição energética residencial e o acesso a serviço e nergéticos limpos: u ma análise a partir de dois estudos de caso. 77 f. Dissertação (Mestrado - Programa de Pós-Graduação em Energia) - Universidade de São Paulo, São Paulo, 2013.

SILVA, E. M. da; SILVA, E. M. da; GONÇALVES, V.; MUROLO, A. C. Estatística para os Cursos de: Economia, Administração e Ciências Contábeis. São Paulo: Atlas, 2011.

SIMIONI, F. J.; HOEFLICH, V. A. Cadeia produtiva de biomassa de origem florestal no planalto sul de Santa Catarina. Floresta, Curitiba, v. 39, n. 3, p. 501 - 510, 2009.

TER BRAAK, C. J. F.; SMILAUER, P. C. Reference manual and user's guide to canoco for windows: Software for Canonical Community Ordination (version 4), Ithaca, New York, USA, Microcomputer Power. 1998.

UHLIG, A. Woodfuels in Brazil: supply-demand balance and the methods for consumption estimation. 1. ed. Saarbrucken: VDM Verlag Dr. Muller, 2010.

VALE, A. T.; RESENDE, R.; GONÇALEZ, J. C.; COSTA, A. F. da. Estimativa do consumo residencial de lenha em uma pequena comunidade rural do município de São João D'Aliança, GO. Ciência Florestal, Santa Maria, v. 13, n. 2, p. 159 - 165, 2003. 